\title{
Describing the evolution of mobile technology usage for Latino patients and comparing findings to national mHealth estimates
}

RECEIVED 4 June 2015

REVISED 20 October 2015

ACCEPTED 30 November 2015

PUBLISHED ONLINE FIRST 19 March 2016

Sanjay Arora, Kelsey Ford, Sophie Terp, Tiffany Abramson, Ryan Ruiz, Marissa Camilon, Christopher J Coyne, Chun Nok Lam, Michael Menchine, Elizabeth Burner

ABSTRACT

Objectives Describe the change in mobile technology used by an urban Latino population between 2011 and 2014, and compare findings with national estimates.

Materials and Methods Patients were surveyed on medical history and mobile technology use. We analyzed specific areas of mobile health capacity stratified by chronic disease, age, language preference, and educational attainment.

Results of 2144 Latino patients, the percentage that owned a cell phone and texted were in-line with Pew estimates, but app usage was not. Patients with chronic disease had reduced access to mobile devices $(P<.001)$ and lower use of mobile phone functionalities.

Discussion Prior research suggests that Latinos can access mHealth; however, we observed lower rates among Latino patients actively seeking heath care.

Conclusion Published national estimates do not accurately reflect the mobile technology use of Latino patients served by our public safety-net facility. The difference is greater for older, less educated patients with chronic disease.

Keywords: Mobile health, Latinos, text messaging, public health

\section{BACKGROUND AND SIGNIFICANCE}

Due to insurance costs, transportation difficulties, language discordance, and many other barriers, minority and disenfranchised populations have difficulty accessing health information. ${ }^{1,2}$ Mobile health (mHealth) uses interventions delivered via mobile phones for text, instant messaging, email, and smart phone applications (apps) to provide health services. ${ }^{3,4}$ Importantly, mHealth allows providers to reach patient groups who struggle with access to care by expanding communication beyond doctor's offices and hospitals to virtually any location. ${ }^{5}$ Increasingly, health care providers and systems are looking to mHealth interventions to efficiently provide health resources to patients using a technology they already own..$^{4,6-8}$

Latino patients in particular are often confronted with significant barriers to establishing care and often have less knowledge of and access to preventive care information. ${ }^{2,9,10}$ In the United States, Latinos are the least likely ethnic group to have health insurance and a medical home. ${ }^{1,11,12}$ Additionally, traditional methods of health education may not account for Latino-specific language and cultural barriers. ${ }^{13,14}$ As suggested by Victorson et al. ${ }^{12}$ in the eSalud paper, all these factors combine to make Latinos ideal targets for culturally appropriate and effective mHealth interventions.

Although limited, the few studies focused on this have shown that the United States Latino population has the access, ability, and desire to effectively utilize mHealth. ${ }^{12,15-17}$ One recent study demonstrated low-income Latinos had a higher demand for mHealth information than their non-Hispanic White, Black, and Asian counterparts. ${ }^{18}$ In 2011, the Pew Research Center, a nonprofit, nonpartisan think tank, released a report, Latinos and Digital Technology, stating that
Latino-American mobile phone ownership had grown from $80 \%$ to $86 \%$ between 2009 and $2010 .{ }^{17}$ However, successful mHealth programs require that patients not only own phones but also have the knowledge to access and use the functions their phones have. ${ }^{19}$ The Pew report states that Hispanics exceed their non-Hispanic White counterparts in accessing the Internet, sending/receiving email, and sending/receiving instant messages on mobile phones. ${ }^{17}$ However, the Pew results are based on a random sample of the Latino population, and are unable to demonstrate whether patients who are actively seeking health resources share this level of mobile phone ownership and knowledge.

\section{OBJECTIVES}

To evaluate the percentage of Latino patients presenting to an urban safety-net facility that own mobile phones and describe their knowledge of specific phone functionalities over time, with particular emphasis on patients with chronic disease.

\section{MATERIALS AND METHODS}

We performed a cross-sectional survey of consecutive adult patients in 2 waves at (Los Angeles County Hospital of the University of Southern California) LAC + USC Medical Center, one of the largest safety-net health care systems in the United States. Trained research assistants (RAs) approached patients in the emergency department and 3 county-sponsored general medicine clinics between July 2011 and May 2012. The survey was repeated with a second sample of consecutive patients between July and August 2014. RAs systematically enrolled patients during normal business hours. All patients were

Correspondence to Sanjay Arora, MD, Keck School of Medicine of the University of Southern California, Department of Emergency Medicine, 1200 North State Street, Room 1011, Los Angeles, CA 90033, USA; Sanjay.arora@usc.edu

(C) The Author 2016. Published by Oxford University Press on behalf of the American Medical Informatics Association. All rights reserved. For Permissions, please email: journals.permissions@oup.com 
surveyed on their demographic data including gender, age, race, ethnicity, language preferences, education level, marital status, and country of birth. Patients self-evaluated their overall health and chronic diseases. We evaluated patients' mobile phone knowledge using questions from the 2010 Pew Report (questions in Appendix A). Patients were excluded if they were critically ill, had altered mental status, did not speak either English or Spanish, or were unable or unwilling to provide consent. RAs administered surveys verbally if study participants preferred to have questions read to them. Approval was obtained from our local IRB prior to study initiation.

Patients' data were retained for this analysis if they self-identified as Latino/Hispanic. Specific measures of mobile technology use and patient demographics were modeled as categorical variables (see Table 1 for stratification categories). Patients were considered to have a chronic disease if they reported a history of diabetes, high blood pressure, high cholesterol, heart disease, lung disease, liver disease, kidney disease, HIV/AIDS, history of stroke, cancer, arthritis, blindness, depression, or mental health issues. Using chi-squared tests, we compared the 2011 and 2014 percentages of cell phone ownership, ability to send/receive text messages, send/receive email, access the Internet on a mobile phone, the use of nonvoice apps, and the ability to send/receive instant messages. We aggregated data from the 2 survey waves and completed analyses of the specific areas of mobile health capacity stratified by presence or absence of chronic disease, age, language preference, and educational attainment using chisquared tests.

\section{RESULTS}

A total of 5146 patients were screened for eligibility in our study (1155 patients in 2011 and 3991 in 2014). A total of 1943 patients were ineligible to participate because they were critically ill, had altered mental status, were currently in police custody/psychiatric ward, were non-English/non-Spanish speaking, were under 18 years old, had taken the survey previously, or listed no documented reason. Of 3203 eligible patients, $89.1 \%$ were enrolled in our study. Of the 2855 patients who provided consent, 711 were removed as they did not selfidentify as being Latino or Hispanic, leaving a final sample for analysis of 2144 patients. Details regarding study inclusion are summarized in Figure 1. Latino patients' demographics were similar between the 2 time periods. Respondents were on average 48 years old and were $51 \%$ male, and only $13 \%$ of patients had college- or graduate-level education. The majority of respondents were foreign born (79\%), and

Table 1: Knowledge of mobile phone functionality of Latino patients at LAC+USC medical center stratified by patient demographics

\begin{tabular}{|c|c|c|c|c|c|c|c|c|c|c|c|c|}
\hline & \multicolumn{2}{|l|}{$\begin{array}{l}\text { Cell phone } \\
\text { ownership }\end{array}$} & \multicolumn{2}{|c|}{$\begin{array}{l}\text { Ability to send/ } \\
\text { receive text } \\
\text { messages }\end{array}$} & \multicolumn{2}{|c|}{$\begin{array}{l}\text { Access any } \\
\text { nonvoice } \\
\text { application }\end{array}$} & \multicolumn{2}{|c|}{$\begin{array}{l}\text { Access the } \\
\text { Internet }\end{array}$} & \multicolumn{2}{|c|}{$\begin{array}{l}\text { Ability to } \\
\text { send/receive } \\
\text { email }\end{array}$} & \multicolumn{2}{|c|}{$\begin{array}{l}\text { Ability to send/ } \\
\text { receive instant } \\
\text { messages }\end{array}$} \\
\hline & $\mathrm{N}(\%)$ & $P$-values & $\mathrm{N}(\%)$ & $P$-values & $N(\%)$ & $P$-values & $\mathrm{N}(\%)$ & $P$-values & $N(\%)$ & $P$-values & $\mathrm{N}(\%)$ & $P$-values \\
\hline Age & & $<.001$ & & $<.001$ & & $<.001$ & & $<.001$ & & $<.001$ & & $<.001$ \\
\hline $18-29$ & $253(87)$ & & $247(85)$ & & $179(62)$ & & $219(76)$ & & $174(60)$ & & $150(52)$ & \\
\hline $30-49$ & 734 (83) & & $653(74)$ & & $338(38)$ & & $410(46)$ & & $309(35)$ & & $348(39)$ & \\
\hline $50-64$ & 556 (75) & & $342(46)$ & & $102(14)$ & & $131(18)$ & & $116(16)$ & & $125(17)$ & \\
\hline $65+$ & 110 (49) & & $41(18)$ & & 5 (2) & & 4 (2) & & $7(3)$ & & $13(6)$ & \\
\hline Gender & & .757 & & .941 & & .467 & & .411 & & .292 & & .745 \\
\hline Male & $854(77)$ & & $664(60)$ & & $331(30)$ & & $405(36)$ & & $325(29)$ & & $333(30)$ & \\
\hline Female & 799 (77) & & $619(60)$ & & $293(28)$ & & $359(35)$ & & $281(27)$ & & $303(29)$ & \\
\hline Education & & $<.001$ & & $<.001$ & & $<.001$ & & $<.001$ & & $<.001$ & & $<.001$ \\
\hline No schooling completed & $119(60)$ & & $54(27)$ & & $19(10)$ & & $28(14)$ & & $16(8)$ & & $19(10)$ & \\
\hline Primary school & $583(73)$ & & $397(49)$ & & $144(18)$ & & $174(22)$ & & $115(14)$ & & $160(20)$ & \\
\hline High school & 705 (81) & & $606(70)$ & & $317(37)$ & & $396(46)$ & & $315(36)$ & & $325(37)$ & \\
\hline College & 230 (91) & & $213(84)$ & & $136(54)$ & & $158(62)$ & & $154(61)$ & & $127(50)$ & \\
\hline Graduate degree & $16(84)$ & & $13(68)$ & & $8(42)$ & & $8(42)$ & & $6(32)$ & & $5(26)$ & \\
\hline Language preference & & $<.001$ & & $<.001$ & & $<.001$ & & $<.001$ & & $<.001$ & & $<.001$ \\
\hline Spanish & $1146(75)$ & & $815(53)$ & & $333(22)$ & & $422(27)$ & & $306(20)$ & & $393(26)$ & \\
\hline English & 507 (84) & & $468(77)$ & & $291(48)$ & & $342(56)$ & & $300(50)$ & & $243(40)$ & \\
\hline USA-born & & .005 & & $<.001$ & & $<.001$ & & $<.001$ & & $<.001$ & & $<.001$ \\
\hline Yes & 349 (82) & & $323(76)$ & & $211(50)$ & & $243(57)$ & & $209(49)$ & & $165(39)$ & \\
\hline No & $1304(76)$ & & $960(56)$ & & $413(24)$ & & $521(30)$ & & $397(23)$ & & $471(27)$ & \\
\hline Have chronic disease & & $<.001$ & & $<.001$ & & $<.001$ & & $<.001$ & & $<.001$ & & $<.001$ \\
\hline Yes & $1111(75)$ & & $815(55)$ & & $359(24)$ & & $436(29)$ & & $357(24)$ & & $378(25)$ & \\
\hline No & $542(83)$ & & $468(71)$ & & $265(40)$ & & $328(50)$ & & $249(38)$ & & $258(39)$ & \\
\hline
\end{tabular}




\section{Figure 1: Flow chart of patients who met inclusion/exclusion}

criteria for the study population.

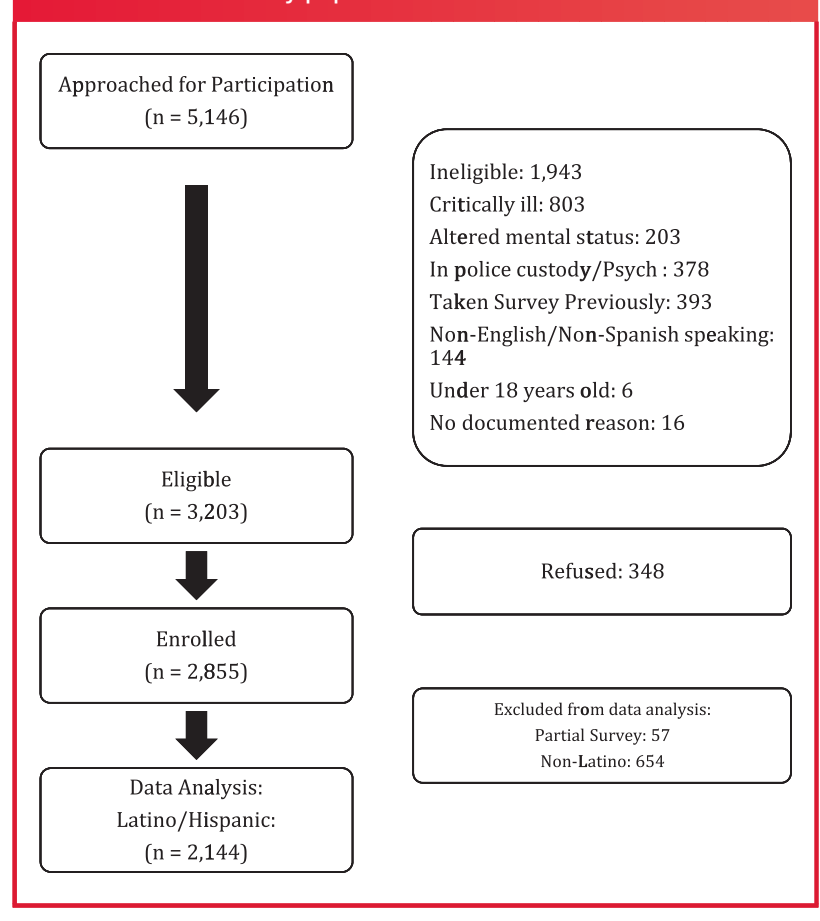

$71.6 \%$ reported Spanish as their preferred language. The majority of patients $(69 \%)$ reported having a chronic disease. Complete patient demographics are summarized in online appendix.

Between 2011 and 2014, the percentage of Latino patients who reported owning a mobile phone increased from $72 \%$ to $79 \%$. Similarly, the percentage of patients who were able to send/receive text messages increased from $54 \%$ to $63 \%$. Regarding more advanced mobile functions, our patients experienced growth over the previous 2 years and either matched or surpassed 2010 Pew estimates in email, Internet use, and instant messages at the end of the survey period. However, app use remained far below Pew estimates from $2010(58 \%)$ despite increasing from 13\% to $36 \%$ over the study period. Full findings regarding patient knowledge of studied mobile phone functionality are detailed in Figure 2.

Patients with a chronic disease had reduced access to mobile devices and lower use of all mobile phone functionalities. A total of $77 \%$ Latino patients in 2011 and 66\% of Latino patients in 2014 reported having a chronic disease. Overall, only $75 \%$ of patients with chronic disease owned a cell phone, compared with $82 \%$ of patients without a chronic disease $(P<.001)$. Similarly, $55 \%$ of patients with a chronic disease sent/received text messages, compared with $71 \%$ of respondents without chronic disease $(P<0.001)$. Despite growth over the study period, patients with chronic disease were less likely to use advanced mobile phone functions. For example, there was a significant difference between patients with chronic diseases who reported using mobile Internet compared with patients without (29\% vs $50 \%$, $P<$.001). Complete details regarding patients with chronic disease are contained in Figure 3.

In examining other patient characteristics that may impact knowledge regarding mobile phone functionality, respondents who were foreign-born, older, had less education, and were less proficient in English used both basic and advanced mobile phone functionalities at significantly lower rates (all $P<.001$ ). For example, $82 \%$ of our respondents aged 18-29 reported sending/receiving text messages, compared with only $22 \%$ of those age $>60$. Of note, more patients in every demographic category examined were able to use text messaging than any of the more advanced mobile functions. Additional details regarding knowledge of mobile phone functionality are broken down by demographic characteristics in Supplemental Table 1.

\section{DISCUSSION}

Overall, our results indicate that mHealth interventions using mobile phones are a viable tool to target low-income Latinos since there is a high penetration of mobile phone ownership in this population. Apps have been used successfully in specific populations, as they can enhance communication with health professionals, are interactive, and contain numerous resources under one platform. ${ }^{21}$ However, our data shows that the vast majority of Latinos seeking health care at our urban safety-net setting cannot use apps. Fortunately, text-messagebased programs have had similar success at targeting hard-to-reach populations. ${ }^{20}$ Arora et al. ${ }^{22}$ used a text-message-based program to target patients seen in the emergency department with poorly controlled diabetes and were able to demonstrate patient satisfaction as well as improved medication adherence. Vyas et al. ${ }^{23}$ used text messaging to successfully educate Latino adolescents about sexual/reproductive health. To date, there are no studies directly comparing the effectiveness of apps against text-message-based programs. It is possible that if apps are shown to be more effective, they may have a greater impact on population health despite the fact that penetration is lower. However, without this evidence, text-message-based solutions hold great promise due to the fact that they are accessible to a significantly larger proportion of patients who can benefit from mHealth.

Building successful mHealth programs for Latinos requires that messages be accurate, relevant, and respectful of patients' cultural norms. ${ }^{12,24,25}$ Per the Centers for Disease Control and Prevention, mHealth programs that are able to achieve this are more likely to be impactful than those that do not deliver messages in a culturally sensitive and language-specific manner. ${ }^{26-28}$ Similarly, messages will need to take into consideration values and attitudes surrounding illness for this patient population. Future research should explore how to design content for mHealth programs that will resonate with Latino patients in order to effect real changes.

\section{LIMITATIONS}

There are several limitations to this study. First, self-reported data on mobile phone use is subject to recall bias. Additionally, study participants' mobile devices were not checked to verify capabilities. So while their phones might have the ability to perform certain functions, survey questions only captured whether patients actively used them. However, our strategy mirrors other national studies regarding mobile phone use, including the Pew Report survey, and, practically, it is what patients can do on their phones that actually matters. Additionally, we sampled Latino patients at a single site. The population of Latino patients in Los Angeles may differ from Latino populations in other parts of the country, limiting the generalizability of findings. Nevertheless, the Los Angeles basin has one of the largest populations of urban, low-income Latinos in the country, making this an optimal location to study a vulnerable population. Lastly, we use Pew report data from 2010 as a comparison to our study population. Given the rapid advance in both mobile technology and affordability, it is possible that the Pew data from 2010 is an underestimate of current mobile technology usage, but they have not yet published a more recent report on Latinos to use as a point for comparison. However, since estimates of current use in our sample are still lower than 2010 


\section{Figure 2: Latino patients' mobile phone fuction usage compared with national estimates.}

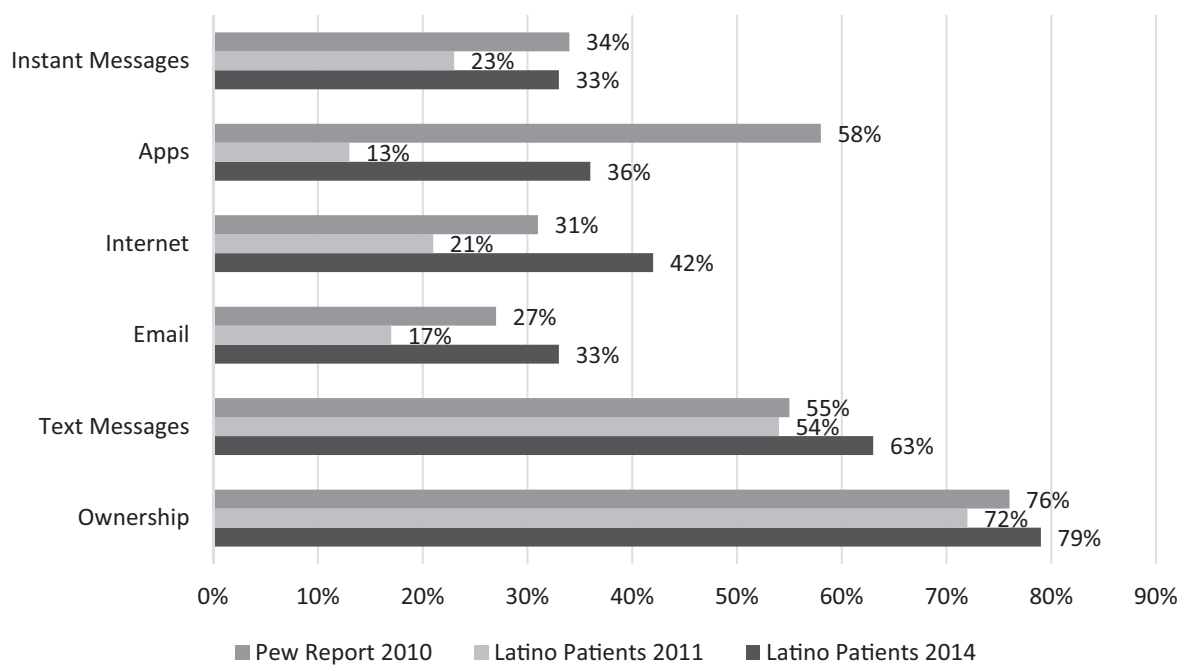

Figure 3: Latino patients with chronic disease mobile phone fuction usage compared with national estimates.

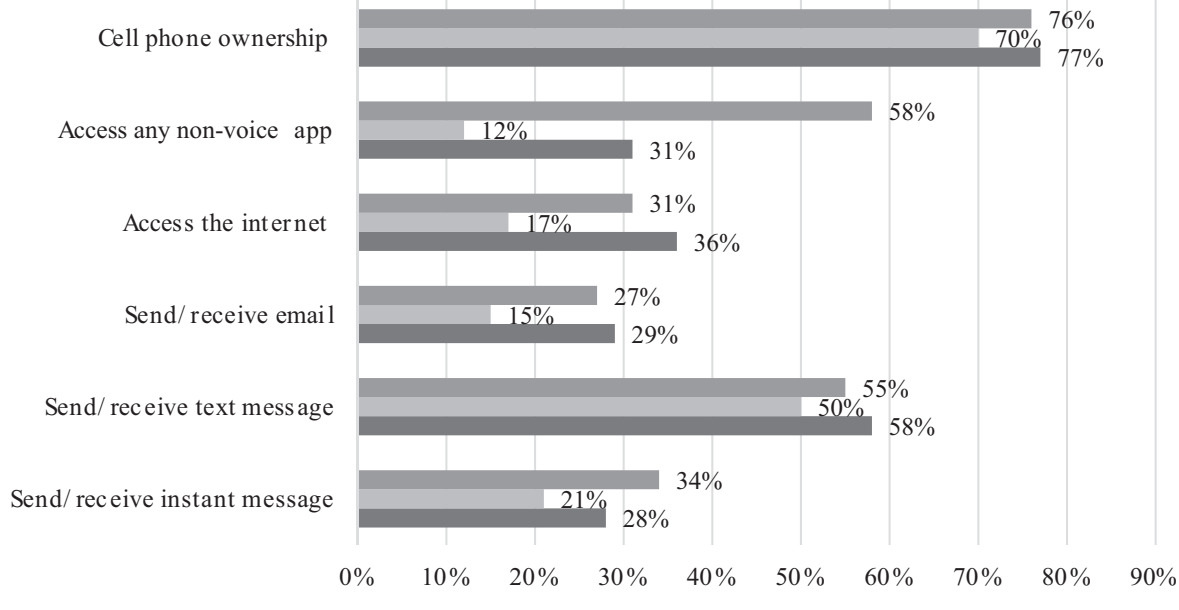

口 Pew Report $2010 \square$ Chronic Disease 2011 a Chronic Disease 2014

estimates, our differences would likely be even greater if compared to more recent national estimates.

\section{CONCLUSION}

Latino patients have traditionally struggled to access medical care in the United States, and as a result have faced health disparities compared to the general population. ${ }^{2,9,10,12}$ mHealth presents a potential solution since it allows health care providers to effectively and efficiently communicate with hard-to-reach, low-income Latinos. However, we found that our patients actively seeking health care use advanced mobile phone functions (email, instant messaging, Internet, and apps) at rates lower than national estimates, and patients with chronic disease fall significantly further behind. Although over the past 3 years, our patients have increased mobile phone use in all categories, their nonvoice app estimates are still below national estimates from 2010, limiting the potential reach of app-based mHealth programs to only $40 \%$ of our population. However, the majority of patients, regardless of chronic disease status, own cell phones and can send/receive text messages. The expansion of mHealth programming has the potential to reduce barriers to health information for resourcepoor Latino patients, but in order to appreciate these benefits, we have to tailor technology toward the specific needs and capabilities of this vulnerable population.

\section{FUNDING}

This work was supported by the US Department of Health and Human ServicesNational Institutes of Health-National Institute of Diabetes and Digestive and Kidney Diseases grant number 1F32DK094547 and the Southern California Southern California Clinical and Translational Science Institute grant number 
KL2TR000131. Both grants provided salary support for Drs Burner and Arora but did not provide specific project funding support.

\section{COMPETING INTERESTS}

The authors have no competing interests to declare.

\section{CONTRIBUTORS}

S.A. had full access to all of the data in the study and takes responsibility for the integrity of the data and the accuracy of the data analysis. S.A., E.B., and M.M. were responsible for study concept and design. T.A., C.N.L., and R.R. were responsible for acquisition of data. K.F., C.C., S.A., T.A., R.R., and E.B. were responsible for analysis and interpretation of data. C.C. was responsible for drafting the article. K.F., S.A., and E.B. were responsible for writing the manuscript. S.A., S.T., C.N.L., M.M., E.B., and K.F. were responsible for statistical analysis, writing, and critical revision of the article for important intellectual content. S.A., E.B., and K.F. take responsibility for the paper as a whole.

\section{SUPPLEMENTARY MATERIAL}

Supplementary material is available online at http://jamia.oxfordjournals.org/.

\section{REFERENCES}

1. Alegria M, Cao Z, McGuire TG, et al. Health insurance coverage for vulnerable populations: contrasting Asian Americans and Latinos in the United States. Inquiry. 2006;43(3):231-254.

2. Beal A, Hernandez S, Doty M. Latino access to the patient-centered medical home. J Gen Int Med. 2009;24(Suppl 3):514-520.

3. Oh H, Rizo C, Enkin M, Jadad A. What is eHealth (3): a systematic review of published definitions. J Med Internet Res. 2005;7(1):e1.

4. Krishna S, Boren SA, Balas EA. Healthcare via cell phones: a systematic review. Telemed J E Health. 2009;15(3):231-240.

5. Schickedanz A, Huang D, Lopez A, et al. Access, interest, and attitudes toward electronic communication for health care among patients in the medical safety net. J Gen Int Med. 2013;28(7):914-920.

6. Liederman EM, Lee JC, Baquero VH, Seites PG. The impact of patientphysician Web messaging on provider productivity. $J$ Healthc Inf Manag. 2005;19(2):81-86

7. Kreps GL, Neuhauser L. New directions in eHealth communication: opportunities and challenges. Patient Educ Counsel. 2010;78(3):329-336.

8. Rimer BK, Kreuter MW. Advancing tailored health communication: a persuasion and message effects perspective. J Commun. 2006;56:S184-S201.

9. Ortega AN, Fang H, Perez VH, et al. Health care access, use of services, and experiences among undocumented Mexicans and other Latinos. Arch Int Med. 2007;167(21):2354-2360.

10. Rodriguez MA, Bustamante AV, Ang A. Perceived quality of care, receipt of preventive care, and usual source of health care among undocumented and other Latinos. J Gen Int Med. 2009;24(Suppl 3):508-513.

11. Shah NS, Carrasquillo 0. Twelve-year trends in health insurance coverage among Latinos, by subgroup and immigration status. Health Affairs (Project Hope). 2006;25(6):1612-1619.
12. Victorson D, Banas J, Smith J, et al. eSalud: designing and implementing culturally competent ehealth research with latino patient populations. $A m$ Public Health. 2014;104(12):2259-2265.

13. Clayman ML, Manganello JA, Viswanath K, Hesse BW, Arora NK. Providing health messages to Hispanics/Latinos: understanding the importance of language, trust in health information sources, and media use. $J$ Health Commun. 2010;15(Suppl 3):252-263.

14. Lindberg N. Challenges in culturally-tailored weight-loss interventions for Hispanic women. Obesity. 2011;19:S117.

15. Ahlers-Schmidt CR, Chesser A, Brannon J, et al. "Necesita una vacuna": what Spanish-speakers want in text-message immunization reminders. J Health Care Poor Underserved. 2013;24(3):1031-1041.

16. Leite L, Buresh M, Rios N, Conley A, Flys T, Page KR. Cell phone utilization among foreign-born Latinos: a promising tool for dissemination of health and HIV information. J Immigr Minor Health. 2014;16(4):661-669.

17. Livingston G. Latinos and Digital Technology, 2010. PEW Internet \& American Life Project February 9, 2011.

18. Ahlers-Schmidt CR, Hart T, Chesser A, Paschal A, Nguyen T, Wittler RR. Content of text messaging immunization reminders: what low-income parents want to know. Patient Educ Counsel. 2011;85(1):119-121.

19. Raphael JL, Zhang Y, Liu H, Tapia CD, Giardino AP. Association of medical home care and disparities in emergency care utilization among children with special health care needs. Acad Pediatr. 2009;9(4):242-248.

20. Lopez L, Grant RW. Closing the gap: eliminating health care disparities among Latinos with diabetes using health information technology tools and patient navigators. J Diab Sci Technol. 2012;6(1):169-176.

21. Burbank AJ, Lewis SD, Hewes M, et al. Mobile-based asthma action plans for adolescents. J Asthma. 2015;52(6):583-586.

22. Arora S, Peters AL, Burner E, Lam CN, Menchine M. Trial to examine text message-based mHealth in emergency department patients with diabetes (TExTMED): a randomized controlled trial. Ann Emerg Med. 2014;63(6):745-754.e6.

23. Vyas AN, Landry M, Schnider M, Rojas AM, Wood SF. Public health interventions: reaching Latino adolescents via short message service and social media. J Med Internet Res. 2012;14(4):e99.

24. Price M, Williamson D, McCandless R, et al. Hispanic migrant farm workers' attitudes toward mobile phone-based telehealth for management of chronic health conditions. J Med Internet Res. 2013;15(4):e76.

25. Ford-Paz RE, Reinhard C, Kuebbeler A, Contreras R, Sanchez B. Culturally tailored depression/suicide prevention in Latino youth: community perspectives. J Behav Health Services Res. 2015;42(4):519-533.

26. Maibach EW, Weber D, Massett H, Hancock GR, Price S. Understanding consumers' health information preferences: development and validation of a brief screening instrument. J Health Commun. 2006;11(8):717-736.

27. Parangimalil GJ. Latino health in the new millennium: the need for a culture-centered approach. Sociol Spectrum. 2001;21(3):423-429.

28. Centers for Disease Control and Prevention (U.S.) OftADoC, Division of Communication Services. Cultural insights; communicating with Hispanics/ Latinos. CDC Stacks Public Health Publications; 2012. http://stacks.cdc.gov/view/cdc/13183.

\section{AUTHOR AFFILIATIONS}

Department of Emergency Medicine, Keck School of Medicine of the University of Southern California, Los Angeles, CA, USA 